\title{
EFFECTS OF GRINDING WHEEL WEAR ON THE THERMO-MECHANICAL LOADS IN THE GRINDING PROCESS
}

\author{
M. Bredthauer ${ }^{1 *}$, T. Bergs ${ }^{1}$, S. Barth ${ }^{1}$, P. Mattfeld ${ }^{1}$ \\ ${ }^{1}$ RWTH Aachen University, Laboratory for Machine Tools and Production Engineering, Aachen, Germany \\ ${ }^{\star}$ Corresponding author; e-mail: M.Bredthauer@wzl.rwth-aachen.de
}

\begin{abstract}
A large amount of the energy produced during grinding is converted into heat. Since not all of the heat can be dissipated by the cooling lubricant, thermally induced displacements in machine components occur, which has a negative influence on the component quality. The generation and distribution of heat is influenced by the change of the grinding wheel topography due to wear.Therefore, the wear mechanisms of grains were identified and quantified and their effect on heat generation was investigated. For this purpose, creep feed grinding investigations on bearing steel were conducted with electroplated CBN grinding wheels with different grain specifications.
\end{abstract}

Keywords:

CBN wear mechanisms; creep feed grinding; heat generation

\section{INTRODUCTION}

The heat transferred into the grinding process through the transformation of kinetic energy can cause thermally induced displacements of machine components and thus has a negative influence on component quality. To predict thermally induced displacements, analytical heat flow calculations were conducted in previous works at LABORATORY FOR MACHINE TOOLS AND PRODUCTION ENGINEERING WZL OF RWTH AACHEN UNIVERSITY as a function of a constant grinding wheel topography to quantify a heat flow distribution into the components grinding wheel, workpiece, chip and cooling lubricant.

The topography of electroplated grinding wheels is continuously changing over the tool life due to wear. The consequences are increasing power losses due to higher friction as well as changed contact and cooling lubricant conditions in the contact zone. This leads to a change in the heat flows during the grinding process and their influence on the thermal deformation field of the machine tool over the tool life. In this respect, the change of the topography and the associated wear mechanisms were both identified and quantified as a function of the grinding wheel life in the presented paper. For this purpose, grinding investigations were conducted with electroplated CBN grinding wheels using as example on bearing steel. With a developed test rig, in which thermocouples were implemented, the change of the heat flow into the workpiece was identified based on the temperature change as a function of the wear condition. This paper presents the results of the experiments which investigate the change of the grinding wheel topography due to wear and its influence on the thermo-mechanica load.

\section{STATE OF THE ART}

In order to identify the problem definition and the knowledge deficit for the presented paper the state of the art is presented in the following. UPADHYAYA and MALKIN [Upadhyaya 2004] demonstrated experimentally on electroplated grinding wheels that in addition to increasing power losses, the heat distribution is influenced due to grinding wheel wear. The heat flows from the grinding process and its influence on the thermal deformation field of a machine tool thus changes over the tool life. The wear of electroplated grinding wheels is characterized by the three main wear mechanisms grain splintering, grain eruption and abrasion [Shi 2003]. In the presented works no changes of characteristic values of the grinding wheel topography were considered. Initial fundamental work by MALKIN and COOK [Malkin 1971] on the wear behavior of grinding tools has shown that there is a direct correlation between grinding force and grain wear. The reduction of grain protrusion by grain flattening was identified as the cause. SHI and MALKIN [Shi 2003] achieved the result for surface grinding and internal cylindrical grinding of the material 100Cr6 with electroplated CBN grinding wheels that stationary grinding wheel wear was characterized by grain splintering. The wear mechanism of the grain flattening had only a minor influence on the tool life. Therefore, SHI and MALKIN correlated in numerical analysis the stationary grinding wheel wear with the maximum undeformed chip thickness $h_{\text {cu,max }}$ [Malkin 2008]. In this respect, the shape of the grains was approximated by a polyeder, which consists of two regular square pyramids. ZEPPENFELD ET AL. [Zeppenfeld 2006] investigated in empirical tests the influence of the maximum undeformed 
chip thickness $h_{\text {cu,max }}$ on the wear mechanisms during the scratching of titanium aluminide with diamond and silicon carbide. They showed that at low maximum undeformed chip thicknesses reduced friction and mechanical stress occure. This was caused by chemical reactions and diffusion processes form adhesive layers on the grain contact surfaces. Flattening of the grain and grain fragmentation due to reduced friction and mechanical stress resulted in a reduction of grinding wheel wear. ARDASHEV [Ardashev 2017] analyzed grinding wheel wear for the first time on a numerical material-physical level on corundum grains. Based on the kinematic solid strength theory, he developed a numerical model that describes grinding wheel wear determined by abrasion during single grain scratching of $\mathrm{C} 45$ with corundum as a function of the grain contact temperature and the grain diameter. The shape of the corundum abrasive grains was idealized by a blunted paraboloid. DING et al. [Ding 2016] investigated the fracture behavior of mono- and polycrystalline CBN grains in empirical invstigations. They identified different wear behavior over time of the two crystal structures. The different wear behavior and the lower wear when using polycrystalline CBN resulted in lower radial wear, lower grinding forces and a lower grinding force ratio. The reason for this is the self-sharpening process due to the microfracture behavior of polycrystalline CBN. In recent works by WIEDERKEHR et al. [Wiederkehr 2018], the influence of grinding wheel wear of electroplated CBN grinding wheels on the grinding force was simulated for the first time based on a data-driven approach. For this purpose, the contour of abrasive grains at different wear conditions of the grinding wheel were measured and modeled by point clouds. For their investigations WIEDERKEHR et al. did not consider characteristic values of the grinding wheel topography. Then, using the grain models from point clouds, a virtual grinding layer of electroplated CBN grinding wheels was modelled and the grinding force was simulated using geometric penetration calculations. In this respect, the linear force model which was used calculated the grinding force based on the local chip cross-sectional areas and was previously calibrated experimentally. BERGS et al. [Bergs 2020a] investigated the CBN fracture behaviour using FEM simulations of single CBN grains. They identified the wear mechanisms as a function of the mechanical load on the grain. In a further work BERGs et al. [Bergs 2020b] simulated the thermo-mechanical contact in single grain scratching depending on the grain shape. The two investigations identified different wear mechanisms of CBN grains and different thermo-mechanical loads depending on their grain shape. However, no transfer to the multi grain contact was made, yet.

Numerous studies were already conducted on the wear behavior of grinding wheels and its effect on the thermomechanical load. However, most of them used idealized grain models or the models can only be used for single grain applications. Consequently, there is no model, which determines the wear of grinding wheels as a function of characteristic values of grinding wheel topography in order to describe the influence on the thermo-mechanical load over the life time of the grinding wheel. Therefore, the aim of the presented research was to identify and quantify the change of the grinding wheel topography as a function of the wear condition of the grinding wheel and to determine the influence of the topography change of the grinding wheel as well as the resulting chracteristic values for the topography on the thermo-mechanical load in the contact zone between the grains and workpiece.

\section{EXPERIMENTAL SETUP}

In this section, the experimental setup and the methodical approach for the empirical investigations to identify and quantify the wear mechanisms and their effects on the thermo-mechanical load collective are presented. The experimental setup is shown in Fig. 1. The empirical investigations were conducted on the surface grinding machine PLANOMAT 620 of the company BLOHM JUNG. The workpieces made of the material $100 \mathrm{Cr} 6(60+1 \mathrm{HRC})$ were ground with single layer electroplated CBN grains with a mean grain diameter $d_{k}=251 \mu \mathrm{m}$ of the company ELEMENT SIX. The grains differed in strength and shape. In order to analyze the investigations in relation to the later identified characteristic values of the grinding wheel topography, a description of the grain shape is omitted. Grain specification 1 had the lowest strength, while grain specifications 2 and 3 had higher but similar strength values. A test rig developed at the WZL by DUSCHA [Duscha 2014] and further developed by BARTH [Barth 2019] was used for the investigations, which enables the measurement of tangential and normal forces resolved over the contact arc $F_{\mathrm{t}, \text { arc }}$ and $F_{\mathrm{n} \text {,arc }}$ as well as the temperatures $T_{\text {arc }}$ resolved over the contact arc of the grinding wheel. A force measuring adapter was used to measure the tangential grinding force $F_{\text {t,arc }}$ resolved over the contact arc and the normal grinding force $F_{\mathrm{n} \text {,arc }}$ resolved over the contact arc. This adapter was clamped in the piezoelectric force transducers and was positioned frictionless to the workpiece halves. The free contact to the surrounding halves of the workpiece ensured that the force curve resolved over the contact arc was exclusively measured via the piezoelectric force transducers. The mean temperature resolved over the contact arc of the workpiece $T_{\text {arc }}$ is determined in this test rig using foil thermocouples type $\mathrm{J}$. Constant grinding parameters were used to determine these process state variables. For the creep feed grinding process, a grinding wheel circumferential speed of $v_{\mathrm{s}}=45 \mathrm{~m} / \mathrm{s}$, a workpiece speed of $v_{\mathrm{w}}=900 \mathrm{~mm} / \mathrm{min}$ and a depth of cut of $a_{\mathrm{e}}=1 \mathrm{~mm}$ were used in the up grinding process. In order to generate the different wear conditions of the grinding wheel, a specific material removal of $V_{w}^{\prime}=140,000 \mathrm{~mm}^{3} / \mathrm{mm}$ was machined with each of the three grinding wheels.

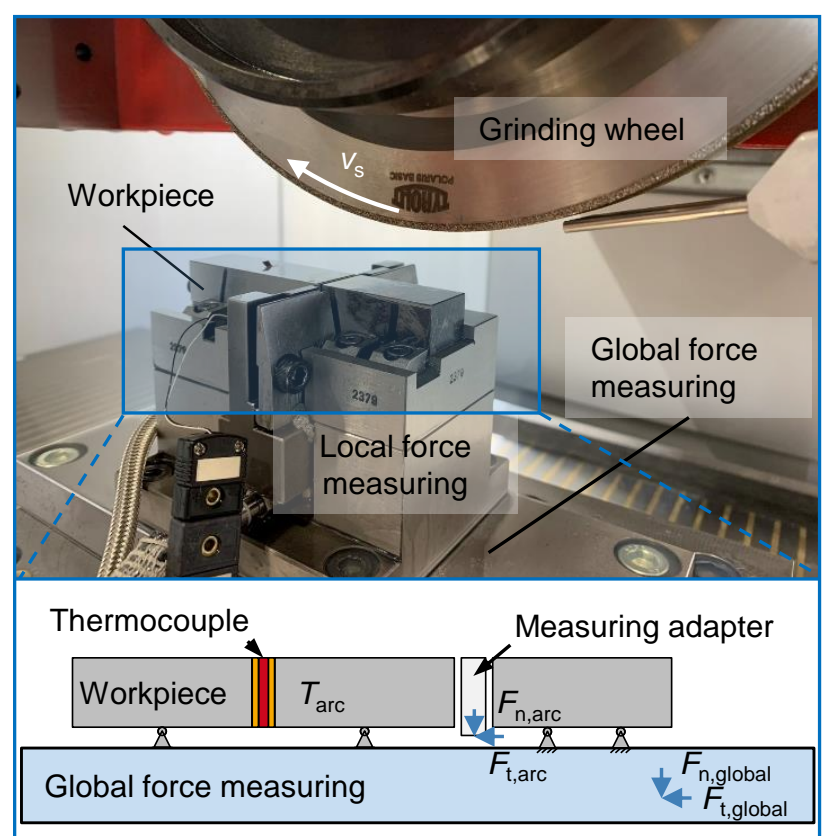

Fig. 1: Experimental Setup according to [Barth 2019] 
To identify and quantify the grinding wheel wear, the wear conditions of each CBN grain specification were identified by molding a negative imprint of the grinding whee topography and measuring by a confocal laser-scanning microscope (LSM). The imprints of the grinding wheel topography with a size of $5 \mathrm{~mm} \times 5 \mathrm{~mm}$ were molded at defined specific material removal $\Delta V_{\mathrm{w}}^{\prime}=5,000 \mathrm{~mm}^{3} / \mathrm{mm}$ in order to determine the different wear conditions in the initial, the stationary and the final wear state. Thus, assigning the respective wear condition to the thermo-mechanical loads recorded by the test rig was possible. For evaluating the grinding wheel wear, correlations between the thermomechanical loads identified as a function of the wear condition of the grinding wheel and the associated characteristic values could be identified.

To evaluate the grinding wheel topography and thus the shape of the grains, the characteristic values of the AbottFirestone curve were determined [DIN 2016]. The AbottFirestone curve and the corresponding characteristic values are shown in Fig. 2. This curve presents the material proportion of the surface as a function of height of the surface and hence describes the increase in the material proportion of a surface with increasing depth of the roughness profile. The Abott-Firestone curve is formed by cutting the profile of a grinding wheel from the highest point to the lowest valley at defined distances from a horizontal plane. For each cut, the percentage of the grinding wheel surface that lies above the cutting plane is calculated. Important components of the Abott-Firestone curve are the core height $S k$, corresponding to the distance between the highest and lowest level of the core of the surface Vmc, the reduced peak height Spk, representing the mean height of the protruding peaks above the core height, and the reduced valley height $S v k$, representing the mean height of the protruding valleys below the core. The reduced grain protrusion $\mathrm{Sg}$ represents the sum of the presented characteristic values of the Abott-Firestone curve. By means of these characteristic values it is possible to evaluate the wear behavior with regard to the wear mechanisms abrasion, micro splintering as well as macro splintering. A change of the reduced peak height Spk at constant core height $S k$ indicates abrasive wear or micro splintering at the grain tip while a reduction of the core height $S k$ indicates larger breakouts.

Furthermore, volume parameters were calculated for the analysis of three-dimensional surface measurements using the Abott-Firestone curve. Two material volume and two void volume parameters are defined as shown in Fig. 2 . The peak material volume $V m p$, the core material volume $V m c$, the void volume of the core $V v c$ and the void volume of the valley $V v v$ are shown.

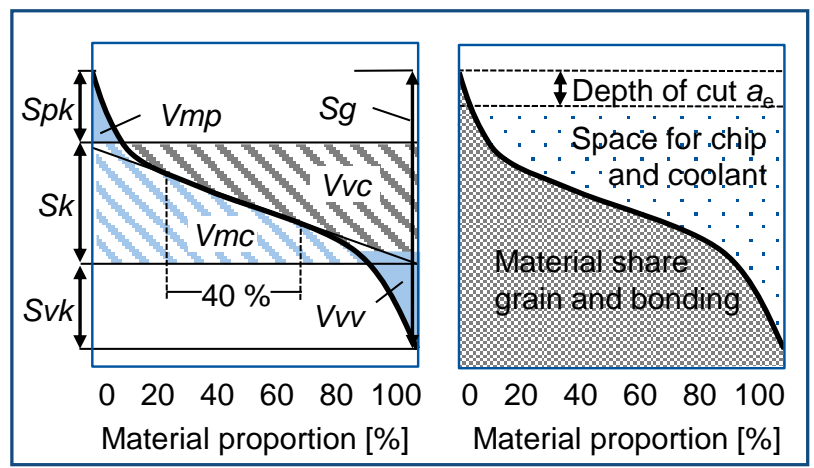

Fig. 2: Surface characteristics of the Abott-Firestone curve according to [DIN 2016] and [Barth 2019]

It is also possible to determine the grain volume $V_{g}$ in defined levels with the help of the topography imprints. For the grain volume determination, a plane to a height $h_{0,1}=50 \mu \mathrm{m}$ below the maximum grain height was used (Fig. 3). This plane was applied to the entire topography of the grinding wheel. By determining the grain volume above the defined level, the wear mechanisms and the wear can be identified as well. In addition, the surface and crosssectional area of the grains above the defined plane are determined to evaluate the grinding wheel topography.

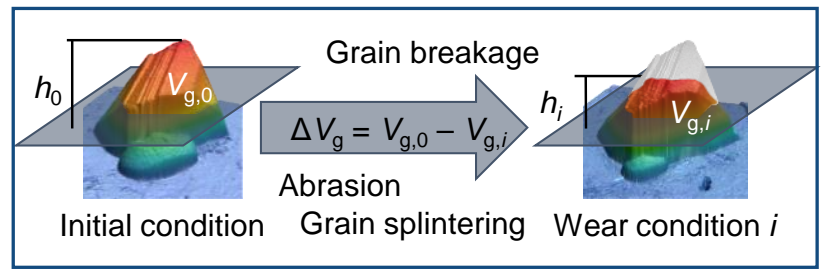

Fig. 3: Grain volume determination

In order to include an evaluation of the grain distance on the grinding wheel surface, a MATLAB tool was developed at LABORATORY FOR MACHINE TOOLS AND PRODUCTION ENGINEERING WZL OF RWTH AACHEN UNIVERSITY. This Tool is detecting the grains on the topography and calculating grain distance distributions as well as grain protrusion distributions. These calculations can be performed in different planes, as it was previously done for grain volume determinations, so that both methods of surface analysis are comparable. The MATLAB tool searches for the bonding area in order to identify the grains based on the defined planes. The grain search identifies the highest points of the topography. In order to exclude that these are not measuring errors but grains, a plane is constructed from the surrounding points of the highest peaks. If it is possible to construct a plane, it is a grain tip. Then a circle with a radius of half a grain diameter is created around the highest points. If there is another grain tip in this circle, it will be deleted, because it is the identical grain. The identified grains are then used to determine the grain distance and grain protrusion distributions.

\section{RESULTS}

In this section, the results of the topography change depending on the wear condition of the grinding wheel as well as the specific material removal and its effect on the thermo-mechanical loads are presented. First, the results of the topography change are presented in chapter 4.1 to explain the change in the thermo-mechanical load which is presented in chapter 4.2.

\subsection{Analysis of the topography change}

\section{Analysis of the grain wear volume}

In the following, the grain wear volume is analyzed by means of the relative grain wear volume $\Delta V_{\text {g,rel. }}$ The relative grain wear volume is determined by $\Delta V_{\mathrm{g}, \mathrm{rel}}=1-V_{\mathrm{g}, i} / V_{\mathrm{g}, 0}$, where $V_{g, 0}$ is the initial volume of the grain topography above a defined plane as described before and $V_{\mathrm{g}, i}$ is the grain volume above the same plane but for another wear condition of the grinding wheel $i$. The result of the relative grain wear volume $\Delta V_{\text {g,rel }}$ in dependence of the specific material removal $V_{w}^{\prime}$ is shown in Fig. 4 for a plane defined $h_{0}=50 \mu \mathrm{m}$ below the highest tip of the topography for each grain specification. The height of the plane was chosen so that the entire wear of the grains (without grain breakage) can be represented. The figure also shows the transitions from the initial to the stationary wear condition of the grinding wheel. In the initial grinding wheel wear condition, irregularly strong increase in the relative grain wear volume occure, whereas the relative grain wear volume increases almost constantly in the stationary grinding wheel wear 
condition. For grain specification 1 and 3 in contrast to grain specification 2, a steeper increase at the end of the investigations was observed, indicating the end of the stationary wear phase. The abortion of the tests was caused by reaching the maximum spindle power of the grinding machine.

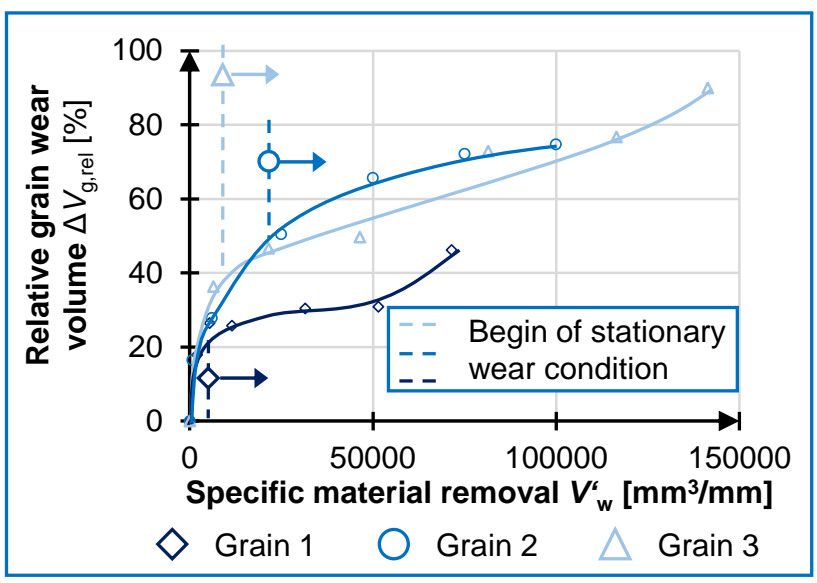

Fig. 4: Results for the relative grain wear volume

The end of the tests was achieved in the tests for grain specification 1 at a specific material removal of $V_{\mathrm{w}}^{\prime}=71,500 \mathrm{~mm}^{3} / \mathrm{mm}$, for grain specification 2 at $V_{w}^{\prime}=100,000 \mathrm{~mm}^{3} / \mathrm{mm}$ and for grain spcification 3 at $V_{w}^{\prime}=141,500 \mathrm{~mm}^{3} / \mathrm{mm}$. By the end of the investigations, a relative grain wear volume of $\Delta V_{\mathrm{g} \text {,rel }}=46.2 \%$ at grain specification $1, \Delta V_{\text {g,rel }}=74.8 \%$ for grain specification 2 and $\Delta V_{\text {g,rel }}=89.9 \%$ for grain specification 3 was achieved. The gradient of the course of the relative grain wear volume up to a specific material removal of $V_{w}^{\prime}=800 \mathrm{~mm}^{3} / \mathrm{mm}$ was similar for the three grain specifications. At this point a relative wear volume of $\Delta V_{\mathrm{g} \text {,rel }}=16-18 \%$ has already been achieved for the three grain specifications. Subsequently, the courses of the relative wear volume of the three grain specifications differ. The course of the relative grain wear volume of grain specification 1 had the flattest course and reached the stationary wear condition of the grinding wheel topography at specific material removal of $V_{\mathrm{w}}^{\prime} \approx 5,000 \mathrm{~mm}^{3} / \mathrm{mm}$. In the stationary wear condition of the grinding wheel the relative grain wear volume increases from $\Delta V_{\text {g,rel }}=20 \%$ to $\Delta V_{\text {g,rel }}=30 \%$. With grain specification 2, the transition of the initial wear condition of the grinding wheel to a stationary grinding wheel wear condition was achieved at a specific material removal of $V_{w}^{\prime} \approx 21,500 \mathrm{~mm}^{3} / \mathrm{mm}$. At the transition between the wear conditions there was no large gradient, so that a transition was difficult to detect. At the transition from initial to stationary wear condition of the grinding wheel of grain specification 2, a relative grain wear volume of $\Delta V_{\mathrm{g}, \text { rel }}=50.4 \%$ was achieved. The relative grain wear volume of grain specification 3 was $\Delta V_{\text {g,rel }}=43.7 \%$ at the transition from initial to stationary wear condition and was achieved at a specific material removal of $V_{\mathrm{w}}^{\prime} \approx 11,000 \mathrm{~mm}^{3} / \mathrm{mm}$. It can be seen that grain specification 3 had a higher gradient during initial wear phase in the course of the relative grain wear volume and grain specification 2 in the stationary wear phase. However, in a comparison of all grains, grain specification 1 showed the lowest gradient in the stationary grinding wheel condition. The grains of grain specification 1 in this condition of wear are therefore probably very stable and are not affected by wear mechanisms other than slight flattening, which does not cause a significant reduction in volume. Since the relative grain wear volume cannot provide detailed information about the wear mechanisms or the change in the characteristic values of the grinding wheel topography, further analyses of the grinding wheel topography have been conducted.

Analysis of the Abott-Firestone curve

The analysis of the characteristic values to describe the grinding wheel topography is presented in the following. In order to identify the change of the topography and thus also of the grain shape, the initial condition of the grinding wheel topography was determined for each grain specification. The topographies of the three grain specifications and their characteristic values of the Abott-Firestone curve are shown in Fig. 5. The topographies of grain specifications 2 and 3 had approximately the same reduced valley height $S v k=14 \mu \mathrm{m}$, while the topography of grain specification 1 had the lowest reduced valley height $S v k=9 \mu \mathrm{m}$. The core height $S k$ and the reduced peak height Spk were different in terms of their absolute size and their proportion of the reduced grain protrusion $\mathrm{Sg}$. The core height of the topography of grain specification 1 with $S k=85.4 \mu \mathrm{m}$ was between the core heights of grain specification 2 with $S k=101.2 \mu \mathrm{m}$ and grain specification 3 with $S k=50.6 \mu \mathrm{m}$. The reduced peak height of grain specification 1 with Spk $=52.4 \mu \mathrm{m}$ was also between the values of grain specification 2 with $S p k=47.9 \mu \mathrm{m}$ and grain specification 3 with $S p k=71.7 \mu \mathrm{m}$. The smaller the reduced peak height Spk and the larger the core height $S k$, the more blocky is the grain.

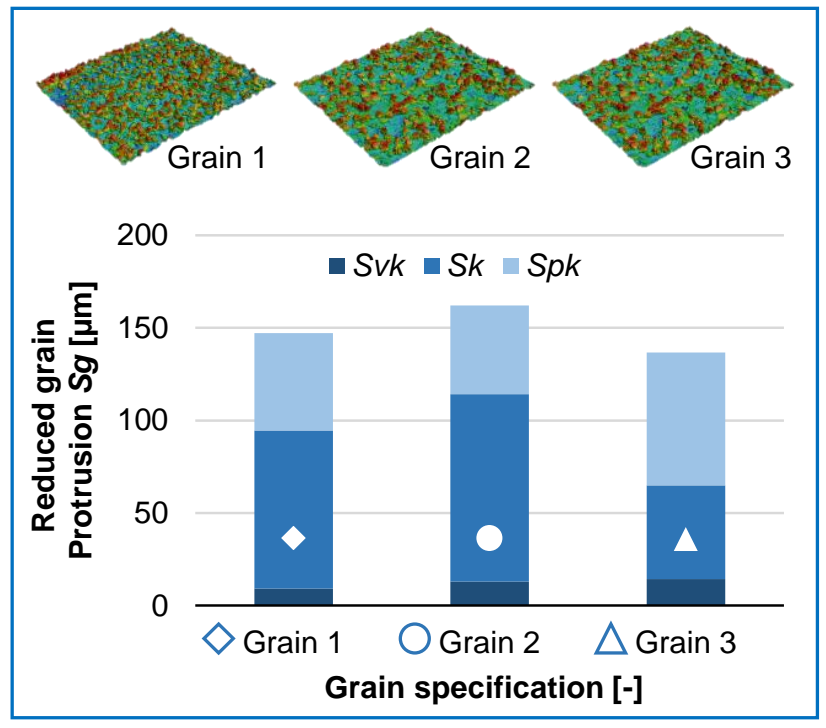

Fig. 5: Initial surface characteristics of the Abott-Firestone curve

The change of the topography is shown in Fig. 6 by the change of the characteristic values of the Abott-Firestone curve depending on the specific material removal $V_{w}^{\prime}$ and the grain specification. While the reduced valley height Svk remains approximately constant for all grain specifications with increasing specific material removal $V^{\prime}$, different changes in the reduced peak height Spk and the core height $S k$ depending on the grain specification were observed. Grain specification 1 showed the lowest change of the characteristic values. The core height $S k=85.4 \mu \mathrm{m}$ changes by $\Delta S k=3.7 \mu \mathrm{m}$ up to a specific material removal of $V_{w}^{\prime}=51,500 \mathrm{~mm}^{3} / \mathrm{mm}$, until it slightly decreases to $S k=76.0 \mu \mathrm{m}$ at a specific material removal of $V_{\mathrm{w}}^{\prime}=71,500 \mathrm{~mm}^{3} / \mathrm{mm}$. The reduced peak height of grain specification 1 increases from $S p k=52.4 \mu \mathrm{m}$ to Spk $=58.6 \mu \mathrm{m}$ with increasing specific material removal $V_{\text {w. }}$. Due to a decreasing core height and an increasing reduced peak height, the reduzed grain protrusion $\mathrm{Sg}$ remains almost constant, because it is the sum of both values. With grain specification 2, the core height 


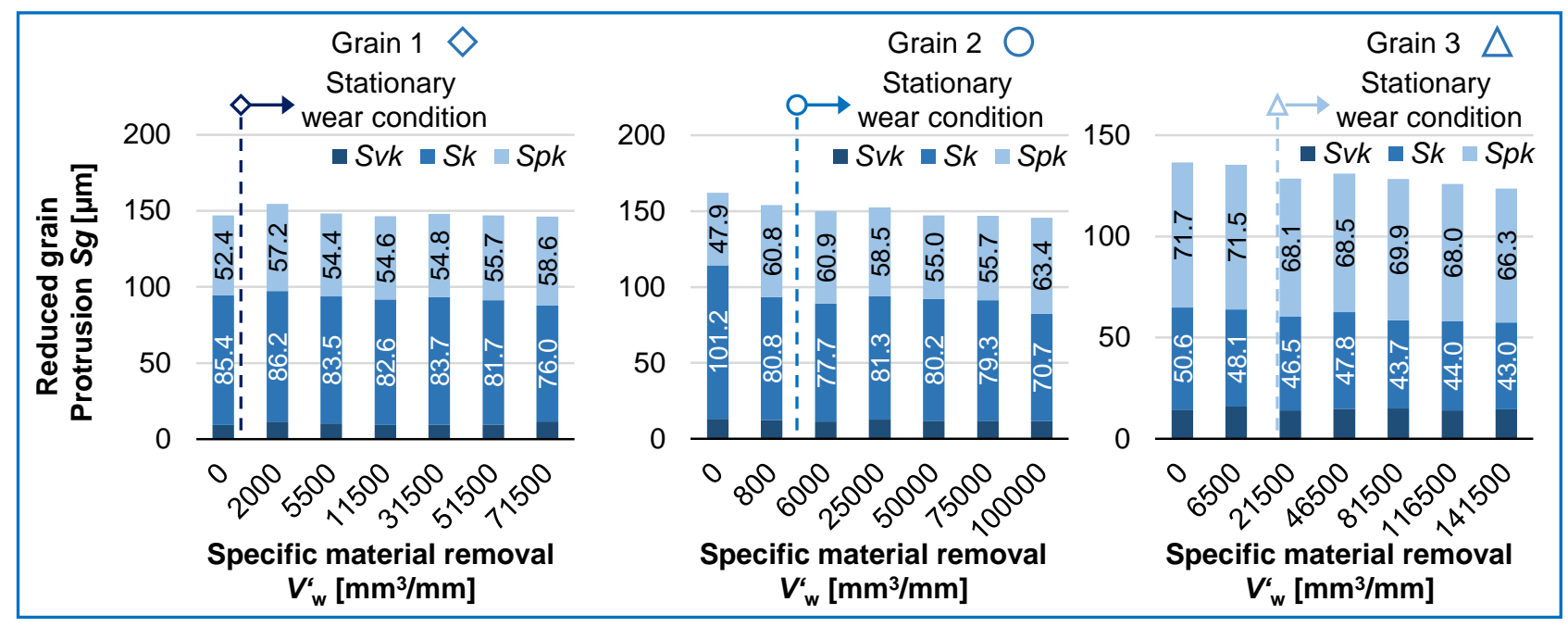

Fig. 6: Change of the topography as a function of the specific material removal

decreases by $\Delta S k=20.4 \mu \mathrm{m}$ in the initial wear condition of the grinding wheel, whereas a slight change occurred in the stationary wear condition of the grinding wheel. Following the stationary wear condition of the grinding wheel, the core height decreased again by $\Delta S k=10 \mu \mathrm{m}$ and reached a core height of $S k=70.7 \mu \mathrm{m}$. The reduced peak height Spk of the topography of grain specification 2 changed contrary to the core height Sk. Thus, the reduced peak height Spk increased during the initial wear condition of the grinding wheel, then decreased very slightly in the stationary wear condition, and finally increased again slightly until it reached a reduced peak height $S p k=63.4 \mu \mathrm{m}$. The core height $S k$ of the topography of grain specification 3 decreased approximately linearly from a core height $S k=50.6 \mu \mathrm{m}$ to a core height $S k=43.0 \mu \mathrm{m}$. The reduced peak height Spk showed the same behavior as the core height $S k$ and decreased almost linearly from $S p k=71.7 \mu \mathrm{m}$ to $S p k=66.3 \mu \mathrm{m}$. Thus, changing the topography of grain specification 3 results in a constant change of the grain tips as well as the grain core and therefore the wear mechanisms do not change with increasing specific material removal. The simultaneous reduction of core height $S k$ and reduced peak height Spk allowed the assumption that the present wear mechanism were macrofractures that reduced both the grain tips and the grain core. With a reduction in peak height Spk and constant core height $S k$ with increasing specific material removal, as it was observed with grain specification 2 during the stationary wear phase, the wear mechanisms were probably flattening due to abrasion and micro splintering. These mechanisms cause a change only at the tip of the grain. When the core height $S k$ decreased and the reduced peak height increased at the same time, as it was observed with grain specification 1 and 2, there was no change in the reduced grain protrusion height $S g$. However, the proportion of the core height $S k$ of the topography was probably reduced by grain macro fracture. In stationary wear condition, grain specification 1 did show slightly relative grain wear volume changes $\Delta V_{\text {g,rel }}$ in contrast to grain specifications 2 and 3 . This behaviour is observed in the slightly changing courses of grain spezification 1 and the higher changing courses of grain specifications 2 and 3 of the characteristics of the Abott-Firestone curve. Although the course of the relative wear volume of grain specification 2 and 3 is similar, the change in the characteristic values of the Abott-Firestone curve is different. While the relative grain wear volume decrease in grain specification 3 was continuously caused by constant wear at the grain tip and grain core, the relative grain wear volume decrease in grain specification 2 was caused by different wear mechanisms. At the end of the stationary condition of the grinding wheel of grain specification 1 and 3 , the relative grain wear volume increases. For grain specification 1, the assumption was made that this is caused by the grain macro-fractures identified by the reduction in core height $S k$. For grain specification 3 , the increase in relative grain wear volume can be explained by abrasion and increased micro splintering at the grain tip (increasing Spk, constant Sk). By the joint consideration of the change of the relative grain wear volume and the characteristic values of the AbottFirestone curve it is possible to describe the wear mechanisms.

\section{Analysis of the grain distribution}

The change of the grain distance distribution above the defined plane due to wear as a function of the specific material removal and the grain specification is shown in Fig. 7 as histograms. The total number of grains $N_{\mathrm{g} \text {,tot }}$ is distributed between the different bins, which cover a range of $d_{g}=100 \mu \mathrm{m}$ as represented in the diagrams. The three grain specifications showed differences in their initial grain distance distribution and their change with increasing specific material removal. In the initial condition of the ginding wheel, the grains on topography of grain specification 1 have the smallest mean grain distance $d_{g}=0.45 \mathrm{~mm}$ and the highest total number of grains $N_{\mathrm{g} \text {,tot }}=169 . \mathrm{Ng}_{\mathrm{g}} / \mathrm{N}_{\mathrm{g} \text {,tot }}=85 \%$ grains of grain specification 1 are distributed over a grain distance between $d_{g}=0.25-0.55 \mathrm{~mm}$. For grain specifications 2 and 3 , the distribution of grain distance is distributed over a larger range, with grain specification 3 having the widest grain distance distribution with $d_{\mathrm{g}}=0.25-0.95 \mathrm{~mm}$. Grain specification 3 also shows a more homogeneous distribution of the grains on the bins. The larger grain distance of grain specification 3 can be explained by the smallest number of grains and the resulting grain density on the grinding wheel topography. For all grain specifications it can be seen that as the specific material removal increased, the grain distance $d_{g}$ increased and the total number of grains $N_{\mathrm{g} \text {,tot }}$ decreased. The reduction in the number of counted grains $N_{g}$,tot was caused by the reduction in grain height due to wear. As a result of the reduction in height, grains which fell below the defined height $h_{0}$ of the plane were no longer evaluated. The least change in the grain distance distribution showed grain specification 1 . This can also be seen in the analysis of the change in the relative grain wear volume $\Delta V_{\text {g,rel }}$, because a slightly increaseing relative grain wear volume $\Delta V_{\text {g,rel }}$ can be identified in a large range of the grinding wheel's life. The 


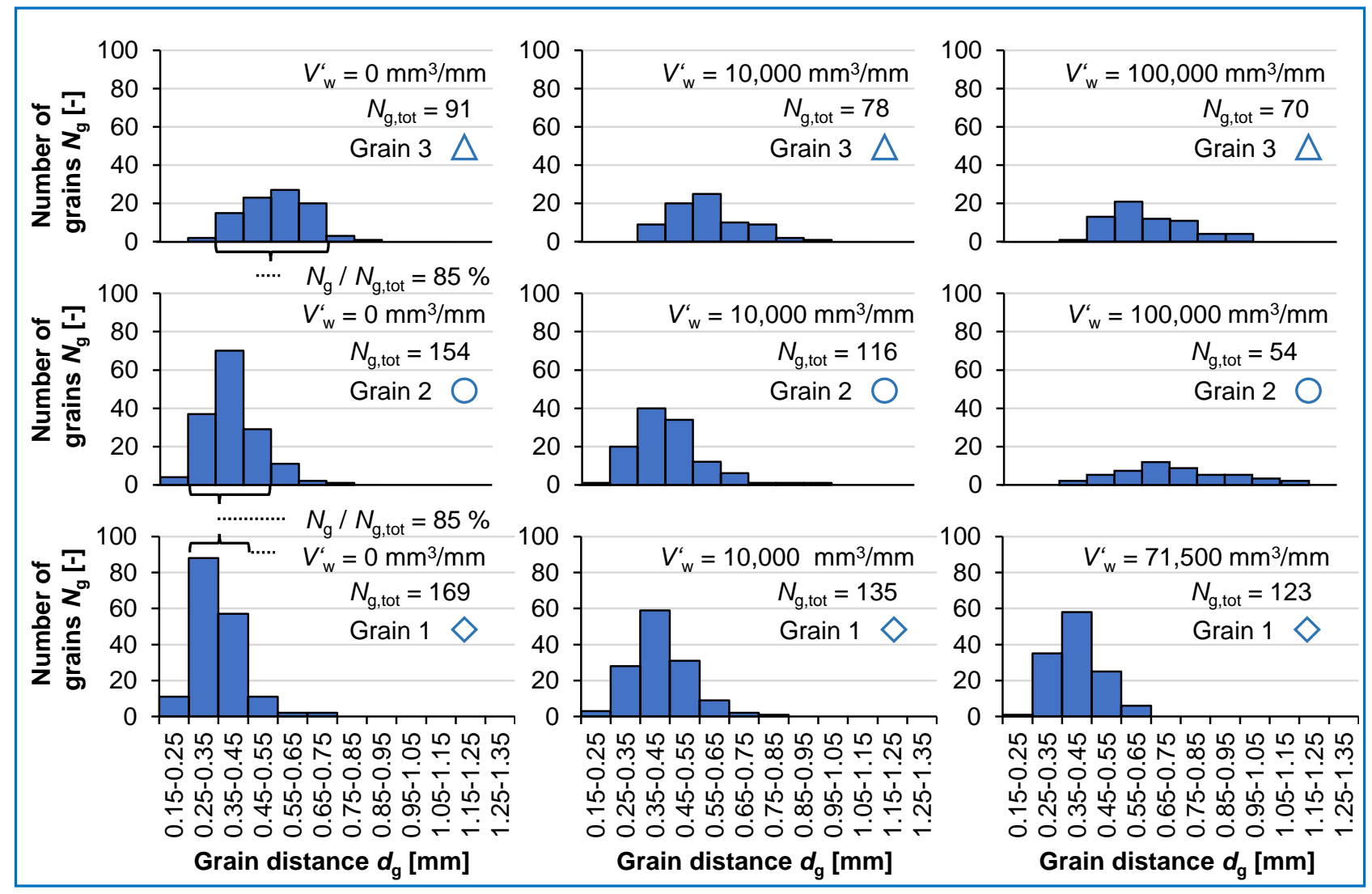

Fig. 7: Change of the grain distance distribution as a function of the specific material removal

largest change in grain distance distribution and the total number of grains $N_{\mathrm{g} \text {,tot }}$ showed grain specification 2. Taking the Abott-Firestone curve into account, this indicates grain breakouts, which can be confirmed by reduced core height. For grain specification 3 the number of bins and the number of grains they contain remains approximately constant with progressing wear of the grinding wheel. However, the grain distance increased. This corresponds to a constant wear curve of the grain tips as reflected by the constant reduction of the core height $S k$ and the reduced peak height Spk.

\subsection{Analysis of the thermo-mechanical load}

In this section the analysis of the resulting thermomechanical load is conducted. Fig. 8 shows a representative force measurement record of the local force $F_{\mathrm{t}, \text { arc }}$ and $F_{\mathrm{n} \text {,arc }}$ resolved over the contact arc as well as the globally recorded forces $F_{\mathrm{t}}$ and $F_{\mathrm{n}}$ as a function of the time. The measurement records have already been processed with a low-pass filter to remove disturbing signals from the machine. The decrease in global forces during the machining of the workpiece resulted from the transition to the measuring plate, since the air gap reduced the required grinding force. Furthermore, the force measurement was overlaid by the force impact of the cooling lubricant, which did not constantly hit the workpiece due to constructional related direction divertion of the cooling lubricant. Therefore, the measuring point for the evaluation of the global force was chosen at the end of the workpiece, since constant cooling lubricant and grinding conditions are given there. While the global force decreases, the local force resolved over the contact arc increases. It can be seen that the forces in the normal and tangential directions $F_{\mathrm{n} \text {,arc }}$ and $F_{\text {t,arc }}$ increase very quickly because the grinding wheel reached the plate in the area of the maximum specific material removal rate $Q_{w}^{\prime}$, which decreased in further grinding and thus also reduced the forces. The influence of the cooling lubricant can also be seen in the curve of the local forces. The maximum force was selected as measuring point for the local forces resolved over the contact arc.

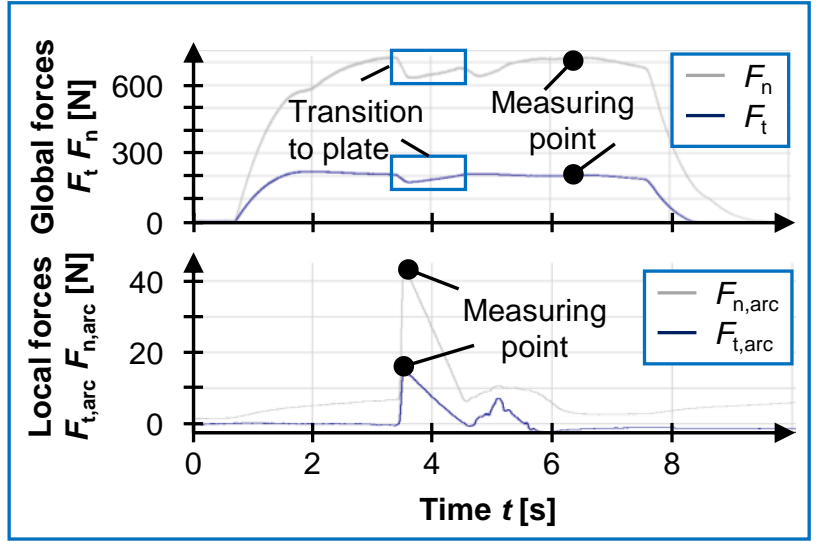

Fig. 8: Exemplary force measurement record

The results of the presented global forces $F_{\mathrm{t}}$ and $F_{\mathrm{n}}$ as well as the local forces $F_{\mathrm{t} \text {,arc }}$ and $F_{\mathrm{n} \text {,arc }}$ recorded over the contact arc as a function of the special material removal $V_{\mathrm{w}}^{\prime}$ are shown in Fig. 9. The forces recorded while machining with the three grain specifications are compared in the diagrams. The course of both local and global forces is almost identical. In the initial wear condition of the grinding wheel, the force initially increased degressively until the stationary wear condition of the grinding wheel was reached with increasing specific material removal $V_{w}^{\prime}$ and an approximately constant increase in force was achieved. Following the stationary wear condition of the grinding wheel, a slightly progressive increase in the forces is visible with increasing specific material removal $V_{\text {w. }}^{\prime}$. In particular the force in the normal direction indicates that the gradient of the force course of the three grains is different. In all wear phases (initial, stationary end of stationary phase), the use of grain specification 1 results in the highest gradient in the 


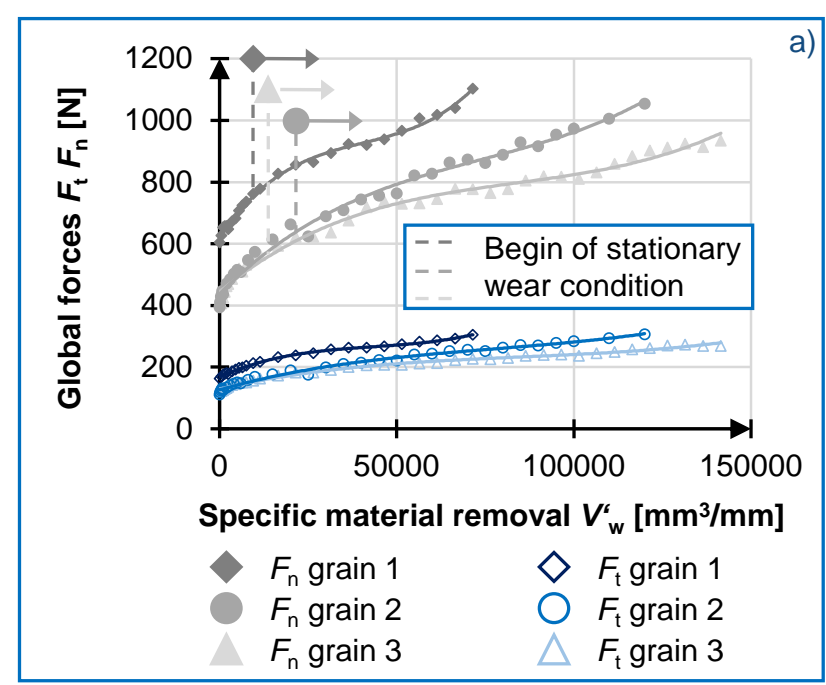

Fig. 9: Results for the global forces $F_{t}$ and $F_{n}$ in a) and the loca course of the forces compared to the other two grain specifications. Not only the gradient of the force course but also the absolutely required grinding forces were highest with grain specification 1 . The maximum global grinding forces when using grain specification 1 in normal and tangential directions were $F_{\mathrm{n}}=1,102 \mathrm{~N}$ and $F_{\mathrm{t}}=334 \mathrm{~N}$, while the highest local forces resolved over the contact arc were $F_{\mathrm{n}, \text { arc }}=67 \mathrm{~N}$ and $F_{\mathrm{t}, \text { arc }}=23 \mathrm{~N}$. The lowest forces at the same specific material removal $V_{w}^{\prime}=71,000 \mathrm{~mm}^{3} / \mathrm{mm}$ were observed when machining with grain specification 3 $\left(F_{\mathrm{n}}=775 \mathrm{~N}, F_{\mathrm{t}}=224 \mathrm{~N}, F_{\mathrm{n}, \operatorname{arc}}=47 \mathrm{~N}\right.$ and $\left.F_{\mathrm{t}, \text { arc }}=18 \mathrm{~N}\right)$. The cutting force ratio $\mu=F_{\mathrm{t}} / F_{\mathrm{n}}$ did not change depending on the grain specification and cutting volume. Only as a function of the local and global force measurement a difference in the cutting force ratio was found. The cutting force ratio of the global force was $\mu=0.29$ and that of the local forces resolved over the contact arc was $\mu=0.40$. Accordingly, the tangential force resolved over the contact arc is significantly higher in relation to the globally acting tangential grinding force. This relationship can be explained by the different geometric engagement conditions over the contact arc of the grinding wheel. The maximum material removal rate is present at the point of the measured forces and therefore the bigger resulting chip formation results in

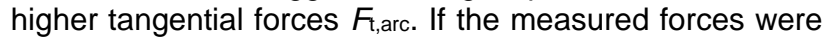
integrated over the contact arc, the cutting force ratio $\mu$ would be identical with the local and global forces.

Analogous to the forces, resolved over the contact arc, the temperature $T_{\text {arc }}$ resolved over the contact arc was recorded and evaluated. The measured temperatures are shown in Fig. 10 as a function of the specific material removal $V_{w}^{\prime}$ and the grain specifications. Similar to the evaluation of the forces, the evaluation of the temperature $T$ arc resolved over the contact arc shows that in the initial phase of wear, the increase of the temperature $T_{\text {arc }}$ resolved over the contact arc was degressive until a steady-state course of the temperature was reached with a stationary wear condition of the grinding wheel. In the stationary wear condition of the grinding wheel, the temperature $T_{\text {arc }}$ resolved over the contact arc increases constantly. A significant increase in temperatures resolved over the contact arc following the stationary range was observed for grain specification 1 and 3 while grain specification 2 increases slightly. The course of the temperatures $T_{\text {arc }}$ is almost parallel to the course of the global and local normal forces $F_{\mathrm{n}}$ and $F_{\mathrm{n} \text {,arc. }}$ The ratio in the absolute temperature difference between the three grain specifications also behaved analogously to the presented forces. Therefore, the temperature resolved over the contact arc $T_{\text {arc }}$ is

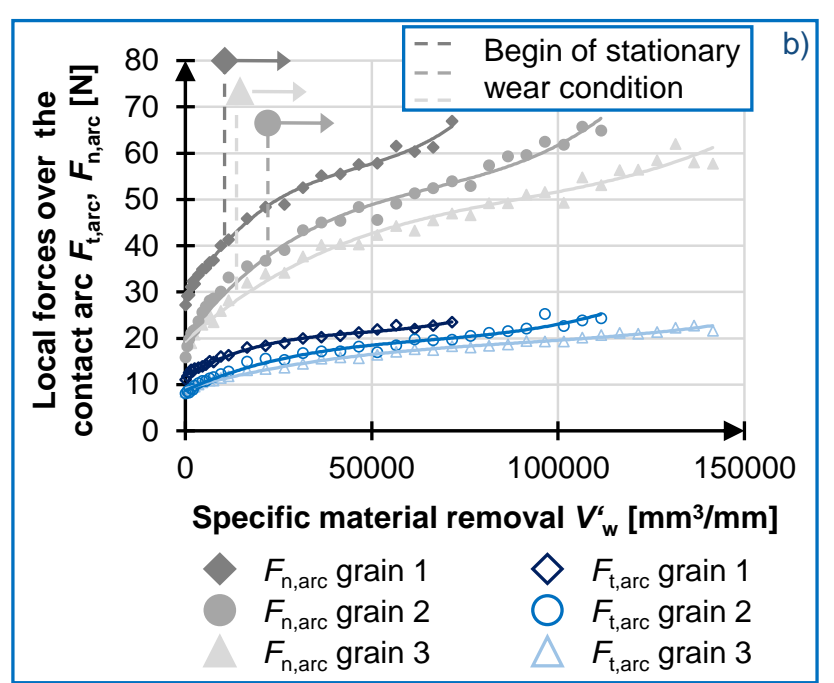

ocal forces resolved over the contact arc $F_{t, \text { arc }}$ and $F_{n, \text { arc }}$ in $\left.b\right)$ approximately linearly dependent on the forces prevailing in the contact zone. An exception was the temperature $T_{\text {arc }}$ from a specific material removal of $V_{\mathrm{w}}^{\prime}=80,000 \mathrm{~mm}^{3} / \mathrm{mm}$. At this time, the temperature of grain specification 2 exceeded the temperature $T_{\text {arc }}=150^{\circ} \mathrm{C}$ of grain specification 3 . The relationship was not reflected in the course of the forces.

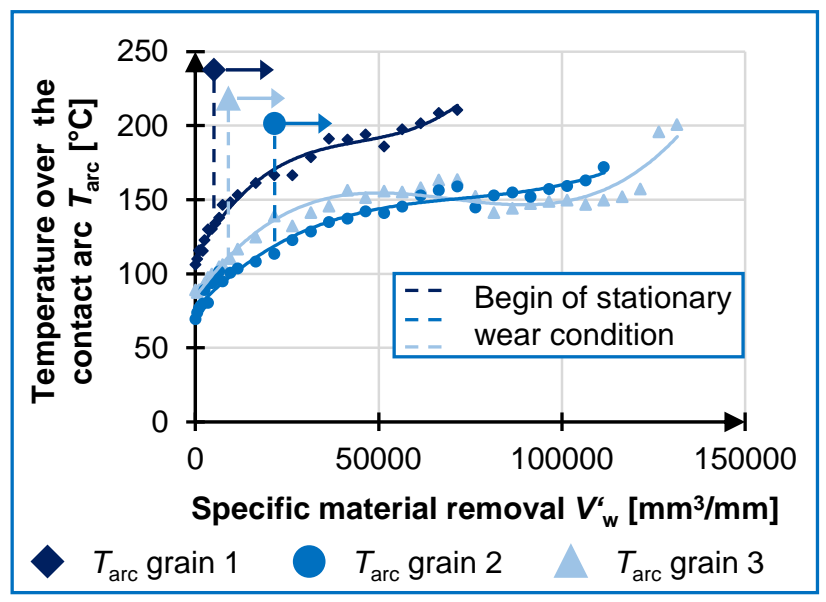

Fig. 10: Results for the temperature resolved over the contact arc

\section{DISCUSSION}

The analysis of the thermo-mechanical load showed that grain specification 1 caused the highest forces and temperatures while grain specification 3 showed the lowest forces during machining. This can be attributed to the number of grains and their grain distribution. A smaller grain distance at the grinding wheel with grain specification 1 results in more cutting edges get into contact with the workpiece. More cinematic cutting edges cause greater friction, which results in higher forces and temperatures. The number of grains as well as the grain distance distribution of grain specification 1 changed the least, whereby the gradient of temperature and forces was also steepest in the stationary wear condition of the grinding wheel. Furthermore, grain specification 1 showed the smallest changes in the characteristic values of the AbottFirestone curve and the relative grain wear volume with increasing specific material removal was the least. This indicates the wear mechanisms abrasion and micro splintering, as these do not cause a significant change in the relative grain wear volume. Since the grain distance did 
not decrease significantly, the grain wear occurred at the grain core. The reduction in volume and macro fractions following the stationary wear condition of the grinding wheel caused a progressive increase in forces and temperatures. The change in the presented characteristic values of the Abott-Firestone curve and the wear mechanisms caused the highest temperature and forces compared to the other grain specifications. In contrast to grain specification 1 , grain specification 3 caused the lowest forces and temperatures up to a specific material removal of $V_{\mathrm{w}}^{\prime}=80,000 \mathrm{~mm}^{3} / \mathrm{mm}$. The small number of grains and the resulting grain distance distribution causes this relation. The reduction in volume at the grain tips and the grain core, which was identified by the reduction of the characteristic values core height $S k$ and reduced peak height Spk resulted in macro-fractures at the grains. Similar to grain specification 1, there was a slight change in the number of grains above the defined plane at height $h_{0}$. This indicates a larger volume decrease in the grain core than in the grain tip. Thereby the temperature and the forces increased stationary with increasing material removal. The temperature $T_{\text {arc }}$ during processing with grain specification 3 in the stationary wear condition of the grinding wheel showed no increase and thus fell below the temperature $T_{\text {arc }}$ of grain specification 2 at a specific material removal $V_{\mathrm{w}}=80,000 \mathrm{~mm}^{3} / \mathrm{mm}$. The reason for the almost stagnating temperature with increasing specific material removal was the significantly increasing grain distance. Due to the increasing grain distance, more cooling lubricant could be entrained in the pore spaces, which allowed the temperature $T_{\text {arc }}$ to be lowered, although the temperature was supposed to increase due to the flattening at the grain tips. The force continued to increase due to the flattening of the grain tips, which is indicated by a reduction in the reduced peak height Spk while the core height Sk remained constant. In summary, it can be stated that an interaction of the presented characteristic values of the Abott-Firestone curve, which provide an indication of the wear mechanisms of the grains, the relative volume, which defines the order of magnitude of the present wear mechanisms, and the grain distance distribution on the grinding wheel topography has a significant influence on the thermo-mechanical load collective. The resulting forces and temperatures in the contact zone between grain and workpiece increase or decrease depending on the extent of the respective effects.

\section{SUMMARY AND OUTLOOK}

In the present paper empirical investigations to identify and quantify the wear mechanisms and their effects on the thermo-mechanical load collective were presented. For this purpose a basic test rig and evaluation methods were used and developed to identify and quantify the wear condition of the grinding wheel and its change as a function of the specific material removal. With the developed analysis methods a wear model could be developed depending on the characteristic values of the grinding wheel topography. By identifying and quantifying the wear conditions as a function of the specific material removal, it was possible to explain the change in the global forces and the forces as well as the temperature resolved over the contact arc. For further research the variation of the grinding parameters is planned in order to be able to set up the wear model depending on the grinding process parameters. In addition, the influence of the characteristic values identified in this paper to describe the effects of the wear condition on the heat flow distribution in the components grinding wheel, workpiece, chip and coolant will be investigated.

\section{ACKNOWLEDGMENTS}

The authors would like to thank the German Research Foundation (DFG) for funding the project "Thermoenergetic Design of Machine Tools" - Project Number 174223256 - TR 96.

\section{REFERENCES}

[Ardashev 2017] Ardashev DV and Shipulin LV. Simulation of grinding with wear of the abrasive grains. Russ. Engin. Res.2017;37(2):150-53.

[Barth 2019] Barth, S. Einfluss der Topographie kunstharzgebundener CBN-Schleifscheiben auf das thermomechanische Belastungskollektiv beim Schleifen. Aachen: Apprimus Wissenschaftsverlag, 2019. ISBN 978-3-86359731-3.

[Bergs 2020a] Bergs, T. et al. Modeling of the fracture behavior of CBN grains during single grain dressing using FEM. Procedia CIRP, 93, 2020,1514-1519.

[Bergs 2020b] Bergs, T. et al. Methodik zur numerischen Simulation des thermo-mechanischen Kontakts beim Einkorneingriff. Diamond Buisiness 2020

[DIN 2016] Deutsches Institut für Normung e. V. DIN EN ISO 25178, 2016.

[Ding 2016] Ding, W.-F. et al. Comparative investigation on wear behavior and self-sharpening phenomenon of polycrystalline cubic boron nitride and monocrystalline cubic boron nitride grains in high-speed grinding. Proceedings of the Institution of Mechanical Engineers, Part B: Journal of Engineering Manufacture, 2016, Vol. 230, No. 4, pp. 710-721. ISSN 0954-4054.

[Duscha 2014]. Beschreibung des Eigenspannungszustandes beim Pendel- und Schnellhubschleifen. Aachen: Apprimus Verl., 2014. ISBN 978-3863592264.

[Malkin 1971] Malkin, S. and Cook, N.H. The Wear of Grinding Wheels: Part 1-Attritious Wear. Journal of Engineering for Industry, 1971, Vol. 93, No. 4, pp. 11201128. ISSN 0022-0817.

[Malkin 2008]. Malkin, S. Guo, C. Grinding technology: theory and application of machining with abrasives. Industrial Press Inc, 2008. ISBN 0831132477.

[Shi 2003] Shi, Z. and Malkin, S. An investigation of grinding with electroplated CBN wheels. CIRP Annals, 2003, Vol. 52, No. 1, pp. 267-270. ISSN 00078506.

[Upadhyaya 2004] Upadhyaya, R.P. and Malkin, S. Thermal Aspects of Grinding With Electroplated CBN Wheels. Journal of Manufacturing Science and Engineering, 2004, Vol. 126, No. 1, pp. 107-114. ISSN 1087-1357.

[Wiederkehr 2018] Wiederkehr, P. et al. Stochastic modeling of grain wear in geometric physically-based grinding simulations. CIRP Annals, 2018, Vol. 67, No. 1, pp. 325-328. ISSN 00078506.

[Zeppenfeld 2006] Zeppenfeld, C. and Klocke, F. Speed Stroke Grinding of $\mathrm{y}$-Titanium Aluminides. CIRP annals, 2006, 55. Jg., Nr. 1, S. 333-338. 